\title{
Chemotoxicity in Carcinoma Breast Patients - Its Incidence and Trends in Severity - An Observational Study
}

\author{
Meenakshi Eknath Yeola1, Aditya Prabhakar Rao Borgaonkar² \\ 1, 2 Department of Surgery, Jawaharlal Nehru Medical College, Sawangi Meghe, Wardha, Maharashtra, India.
}

\section{ABSTRACT}

\section{BACKGROUND}

Chemotherapy has improved the survival of the carcinoma breast patients. But the use of cytotoxic drugs causes multiple chemotoxicities such as nausea, vomiting, weight changes and leucopenia reducing the quality of life of the patients, thereby making the patients defaulters and thus, increasing the chances of recurrence. Very few studies were done in India where patients have different physical, mental, social \& cultural characteristics that affect the response \& outcomes of treatment differently. We wanted to assess the prevalence \& severity of chemotoxicity in carcinoma breast patients receiving chemotherapy along with its comparison amongst commonly used regimens of chemotherapy.

\section{METHODS}

Fifty female patients diagnosed with carcinoma breast (excluding the ones having poor performance status, receiving chemotherapy with different regimes) were included in this single centre study. Prevalence and trends of different chemotoxicities like hair loss, nausea, vomiting, fatigue, leucopenia, thrombocytopenia, weight changes were observed using Common Terminology Criteria for Adverse Events version 4 (CTCAE V4.0) guidelines and were compared at the end of $1^{\text {st }}, 3^{\text {rd }} \& 6^{\text {th }}$ cycle of chemotherapy. Categorical variables were presented in numbers and percentages (\%) and continuous variables were presented as mean \pm SD and median. Qualitative variables were correlated using chi-square test / Fisher's exact test. A P value of $<0.05$ was considered statistically significant. The data was analysed using Statistical Package for Social Sciences (SPSS) version 21.0.

\section{RESULTS}

Hair loss was detected in $98 \%$ of patients with increasing trend of severity; nausea \& vomiting were experienced by $100 \%$ \& $54 \%$ respectively, with decreasing trend of severity. One patient suffered with extravasation of chemotherapeutic drug, $52 \%$ of patients had nail changes with non-significant trend in severity, $24 \%$ patients experienced weight gain while rest had weight loss. All of the patients experienced varying grades of fatigue with increasing trend of severity. Leukopenia was seen single or multiple times (21 times) amongst 16 patients during chemotherapy, while thrombocytopenia was observed 22 times among 15 patients. There was no prevalence of neuropathy, cardiotoxicity, and oral ulcers; also, there was minimal prevalence of severe grades of chemotoxicity with no life-threatening event.

\section{CONCLUSIONS}

Hair loss and nausea were seen with increasing and decreasing tendency respectively. No particular regimen was found to be more toxic or safer than the other. With the prevalence and severity trends, patients can be counselled properly regarding chemotoxicity and prepared for these adverse effects. This would have lesser impact on the quality of life.

\section{KEY WORDS}

Chemotherapy, Chemotoxicity, Alopecia, Nausea, Vomiting, Fatigue, Leukocytopenia, Thrombocytopenia, Carcinoma Breast
Corresponding Author: Dr. Aditya Prabhakar Rao Borgaonkar, Department of Surgery, Jawaharlal Nehru Medical College, Sawangi Meghe, Wardha, Maharashtra, India. E-mail: adityarsml08@gmail.com

DOI: $10.14260 / j e m d s / 2021 / 144$

How to Cite This Article:

Yeola ME, Borgaonkar AP. Chemotoxicity in carcinoma breast patients - its incidence and trends in severity - an observational study. J Evolution Med Dent Sci 2021;10(10):667-672, DOI: $10.14260 /$ jemds/2021/144

Submission 03-11-2020,

Peer Review 14-01-2021,

Acceptance 20-01-2021,

Published 08-03-2021.

Copyright (c) 2021 Meenakshi Eknath Yeola et al. This is an open access article distributed under Creative Commons Attribution License [Attribution 4.0 International (CC BY 4.0)] 


\section{BACKGROUND}

Breast cancer is the most common cancer among females worldwide accounting for nearly a quarter (25\%) of all cancers, with an estimated 1.67 million new cancer cases diagnosed in 2012. Women from less developed regions $(8,83,000$ cases $)$ have slightly greater number of cases compared to more developed $(7,94,000)$ regions. ${ }^{1}$ In India, although age adjusted incidence rate of breast cancer is lower (25.8 per 100000 ) than United Kingdom (95 per 100000 ) but mortality is at par (12.7 vs. 17.1 per 100 000) with United Kingdom. ${ }^{2}$ There is a significant increase in the incidence and cancer-associated morbidity and mortality in Indian subcontinent as described in global and Indian studies.3,4,5,6 Now a days, a multimodal approach with combination of surgery, chemotherapy either adjuvant or neoadjuvant and radiotherapy is the standard protocol for almost all stages of breast carcinoma in most of the treatment centres. ${ }^{7}$ Incorporation of chemotherapy in the treatment protocol has improved the survival of the patient. But the use of cytotoxic drugs used in the chemotherapy regimens result in various toxic side effects or chemotoxicities such as nausea, vomiting, fatigue, impairment in cognitive and sexual functioning that eventually reduce the quality of life of the patients undergoing chemotherapy. ${ }^{8}$ Chemotoxicity is a quite common occurrence during chemotherapy which has a high impact value on mindset of the patients, which results in compromise with quality of life of the patient then may end in patient becoming defaulter leading to increased chances of recurrences due to inadequate treatment. Indexed study aimed at assessment of prevalence \& severity of chemotoxicity in carcinoma breast patients receiving chemotherapy along with its comparison amongst commonly used regimens of chemotherapy.

\section{METHODS}

This observational study was conducted at Acharya Vinoba Bhave Rural Hospital, a tertiary care teaching hospital situated in the rural area of Wardha District, from September 2017 to
August 2019. Approval from institutional ethics committee was obtained. [Letter no: DMIMS (DU) / IEC / 2017 - 18 / 6647] Consent was made available both in English and patient's native language \& was taken accordingly. This study included 50 patients after applying inclusion \& exclusion criteria. All the diagnosed patients of carcinoma breast during the study duration who received chemotherapy with adriamycin-cyclophosphamide, cyclophosphamideadriamycin-5FU, adriamycin-cyclophosphamide with paclitaxel \& cyclophosphamide-adriamycin-5FU with paclitaxel regimes were included as per recent National Comprehensive Cancer Network (NCCN) guidelines. The patients who did not consent for the research and having poor performance status (Eastern Cooperative Oncology GroupECOG scale 3 or more $)^{14}$ were excluded. The demographic data of the patients along with the diagnostic criteria were collected. Other information including pre-chemotherapy haemoglobin, total leucocyte count \& platelet count; similarly, post chemotherapy counts were assessed after 7 days of receiving chemotherapy. Chemotoxicity was assessed under thrombophlebitis, extravasation, nail changes, hair loss, nausea, vomiting, neuropathy, cardiotoxicity, weight, appetite, oral ulcer, fatigue, miscellaneous as per Common Terminology Criteria for Adverse Events (CTCAE) version 4 grading system (Table 1).15 All the observed parameters were noted while taking history at the time of admission and during daily rounds as per prevalence and or severity on a scale and their trends in prevalence and severity were compared at the end of first, third and sixth cycles of chemotherapy.

\section{Statistical Analysis}

Categorical variables are presented in number and percentage (\%) and continuous variables are presented as mean \pm SD and median. Qualitative variables were correlated using chisquare test / Fisher's exact test. A P-value of $<0.05$ was considered statistically significant. The data was entered in MS Excel spreadsheet and analysis was done using Statistical Package for Social Sciences (SPSS) version 21.0

\begin{tabular}{|c|c|c|c|c|c|c|}
\hline & Grade 0 & Grade 1 & Grade 2 & Grade 3 & Grade 4 & Grade 5 \\
\hline $\begin{array}{l}\text { Nail } \\
\text { changes }\end{array}$ & None & Discoloration, koilonychia or pitting & $\begin{array}{l}\text { Partial or complete onycholysis or } \\
\text { pain at the nail bed }\end{array}$ & Interfering with activities of daily living & - & - \\
\hline Hair loss & None & $\begin{array}{l}<50 \% \text { of normal, that is not obvious } \\
\text { from a distance but on a close } \\
\text { inspection. }\end{array}$ & $\begin{array}{c}>50 \% \text { of normal that is readily } \\
\text { apparent to others. individual need } \\
\text { wig }\end{array}$ & - & - & - \\
\hline Nausea & None & $\begin{array}{l}\text { Loss of appetite without alteration in } \\
\text { eating habits }\end{array}$ & $\begin{array}{c}\text { Oral intake decreased without } \\
\text { significant weight loss, dehydration or } \\
\text { malnourishment }\end{array}$ & $\begin{array}{l}\text { Inadequate oral calorie or fluid intake; } \\
\text { tube feeding, total parenteral nutrition, } \\
\text { hospitalisation indicated }\end{array}$ & - & - \\
\hline Vomiting & None & 1 - 2 episodes / 24 hrs. & 3 - 5 episodes / $24 \mathrm{hrs}$. & $\begin{array}{c}>6 \text { episodes } / 24 \text { hrs.; tube feeding, total } \\
\text { parenteral nutrition, hospitalisation } \\
\text { indicated }\end{array}$ & $\begin{array}{l}\text { Life threatening } \\
\text { consequences, urgent } \\
\text { intervention required }\end{array}$ & Death \\
\hline Fatigue & None & Fatigue relieved by rest & $\begin{array}{l}\text { Fatigue not relieved by rest, limiting } \\
\text { activities of daily life }\end{array}$ & $\begin{array}{l}\text { Fatigue not relieved by rest, limiting } \\
\text { activities of daily life as well as self-care }\end{array}$ & - & - \\
\hline $\begin{array}{l}\text { Leuco } \\
\text { penia }\end{array}$ & $\begin{array}{l}\text { Within } \\
\text { normal range }\end{array}$ & Lower normal limit - 3000 / ml & $3000-2000 / \mathrm{ml}$ & $2000-1000 / \mathrm{ml}$ & $<1000 / \mathrm{ml}$ & - \\
\hline $\begin{array}{l}\text { Thrombo } \\
\text { cytopenia }\end{array}$ & $\begin{array}{l}\text { Within } \\
\text { normal range }\end{array}$ & Lower normal limit - 75000 / ml & $75000-50000 / \mathrm{ml}$ & $50000-25000 / \mathrm{ml}$ & $<25000 / \mathrm{ml}$ & - \\
\hline
\end{tabular}




\section{RESULTS}

Fifty female patients of carcinoma breast who received chemotherapy with either one of four regimens with mean age of patients at presentation being 50.9 years (mostly in range of 41 - 50 years) were studied for prevalence and severity of chemotoxicities.

\begin{tabular}{|c|c|c|}
\hline Chemotoxicity & Prevalence (with Trend) & Trend of Severity \\
\hline Nail changes & $\begin{array}{c}48 \% \text { (no rising or decreasing } \\
\text { trend) }\end{array}$ & $\begin{array}{l}\text { Increasing (statistically non- } \\
\text { significant trend) }\end{array}$ \\
\hline Hair loss & $98 \%$ (Increasing trend) & $\begin{array}{c}\text { Increasing (statistically significant } \\
\text { trend) }\end{array}$ \\
\hline Nausea & $100 \%$ (decreasing trend) & $\begin{array}{c}\text { Decreasing (statistically significant } \\
\text { trend) }\end{array}$ \\
\hline Vomiting & $54 \%$ (decreasing trend) & $\begin{array}{c}\text { Decreasing (statistically significant } \\
\text { trend) }\end{array}$ \\
\hline Weight gain & $24 \%$ & $\begin{array}{l}\text { Neither increasing nor decreasing } \\
\text { significant trend }\end{array}$ \\
\hline Weight loss & $76 \%$ & $\begin{array}{l}\text { Neither increasing nor decreasing } \\
\text { significant trend }\end{array}$ \\
\hline $\begin{array}{l}\text { Reduction in } \\
\text { appetite }\end{array}$ & $76 \%$ & $\begin{array}{l}\text { Neither increasing nor decreasing } \\
\text { significant trend }\end{array}$ \\
\hline Fatigue & $100 \%$ (increasing trend) & $\begin{array}{c}\text { Increasing (statistically significant } \\
\text { trend) }\end{array}$ \\
\hline Leucopenia & $32 \%$ (increasing trend) & $\begin{array}{c}\text { Increasing (statistically significant } \\
\text { trend) }\end{array}$ \\
\hline Thrombocytopenia & $30 \%$ (increasing trend) & $\begin{array}{l}\text { Increasing (statistically non- } \\
\text { significant trend) }\end{array}$ \\
\hline
\end{tabular}

\begin{tabular}{|c|c|c|c|c|c|}
\hline \multicolumn{2}{|c|}{ Chemotoxicity } & $\begin{array}{c}\text { Nail Changes } \\
\text { (percentage } \\
\text { in bracket) }\end{array}$ & $\begin{array}{c}\text { Hair Loss } \\
\text { (percentage } \\
\text { in bracket) }\end{array}$ & $\begin{array}{l}\text { Vomiting } \\
\text { (percentage } \\
\text { in bracket) }\end{array}$ & $\begin{array}{c}\text { Fatigue } \\
\text { (percentage } \\
\text { in bracket) }\end{array}$ \\
\hline \multirow{4}{*}{$1^{\text {st }}$ Cycle } & Grade 0 & $24(48 \%)$ & 26 (52 \%) & $23(46 \%)$ & $5(10 \%)$ \\
\hline & Grade 1 & 26 (52 \%) & $24(48 \%)$ & $24(48 \%)$ & 45 (90 \%) \\
\hline & Grade 2 & - & 00 & $3(6 \%)$ & 00 \\
\hline & Total & $50(100 \%)$ & $50(100 \%)$ & $50(100 \%)$ & $50(100 \%)$ \\
\hline \multirow{5}{*}{$3^{\text {rd }}$ Cycle } & Grade 0 & $24(48 \%)$ & $1(2 \%)$ & $40(80 \%)$ & $1(2 \%)$ \\
\hline & Grade 1 & $26(52 \%)$ & 37 (74 \%) & $10(20 \%)$ & $34(68 \%)$ \\
\hline & Grade 2 & - & $12(24 \%)$ & 00 & $15(30 \%)$ \\
\hline & Total & $50(100 \%)$ & $50(100 \%)$ & $50(100 \%)$ & $50(100 \%)$ \\
\hline & $P$ value & 0.841 & $<0.0001$ & 0.001 & 0.0001 \\
\hline \multirow{5}{*}{$6^{\text {th }}$ Cycle } & Grade 0 & $24(48 \%)$ & $1(2 \%)$ & 47 (94\%) & 00 \\
\hline & Grade 1 & $26(52 \%)$ & 27 (54 \%) & $3(6 \%)$ & $30(60 \%)$ \\
\hline & Grade 2 & - & $22(44 \%)$ & 00 & $20(40 \%)$ \\
\hline & Total & $50(100 \%)$ & $50(100 \%)$ & $50(100 \%)$ & $50(100 \%)$ \\
\hline & $P$ value & 0.841 & $<0.0001$ & $<0.0001$ & $<0.0001$ \\
\hline
\end{tabular}

\begin{tabular}{|c|c|c|c|c|}
\hline \multicolumn{2}{|c|}{ Chemotoxicity } & $\begin{array}{c}\text { Nausea } \\
\text { (percentage } \\
\text { in bracket) }\end{array}$ & $\begin{array}{l}\text { Leucopenia } \\
\text { (percentage } \\
\text { in bracket) }\end{array}$ & $\begin{array}{l}\text { Thrombocytopenia } \\
\text { (percentage in } \\
\text { bracket) }\end{array}$ \\
\hline \multirow{5}{*}{$1^{\text {st }}$ Cycle } & Grade 0 & 00 & $49(98 \%)$ & $44(88 \%)$ \\
\hline & Grade 1 & $30(60 \%)$ & 00 & $3(6 \%)$ \\
\hline & Grade 2 & $17(34 \%)$ & $1(2 \%)$ & $1(2 \%)$ \\
\hline & Grade 3 & $3(6 \%)$ & 00 & $2(4 \%)$ \\
\hline & Total & $50(100 \%)$ & $50(100 \%)$ & $50(100 \%)$ \\
\hline \multirow{6}{*}{$3^{\text {rd }}$ Cycle } & Grade 0 & $26(52 \%)$ & $39(78 \%)$ & $46(92 \%)$ \\
\hline & Grade 1 & $22(44 \%)$ & $8(16 \%)$ & $4(8 \%)$ \\
\hline & Grade 2 & $2(4 \%)$ & $3(6 \%)$ & 00 \\
\hline & Grade 3 & 00 & 00 & 00 \\
\hline & Total & $50(100 \%)$ & $50(100 \%)$ & $50(100 \%)$ \\
\hline & $P$ value & $<0.0001$ & 0.006 & 0.364 \\
\hline \multirow{6}{*}{$6^{\text {th }}$ Cycle } & Grade 0 & $37(74 \%)$ & $41(82 \%)$ & $45(90 \%)$ \\
\hline & Grade 1 & $13(26 \%)$ & $3(6 \%)$ & $4(8 \%)$ \\
\hline & Grade 2 & 00 & $4(8 \%)$ & $1(2 \%)$ \\
\hline & Grade 3 & 00 & $2(4 \%)$ & 00 \\
\hline & Total & $50(100 \%)$ & $50(100 \%)$ & $50(100 \%)$ \\
\hline & $P$ value & $<0.0001$ & 0.057 & 0.541 \\
\hline
\end{tabular}

\begin{tabular}{|c|c|c|c|}
\hline \multicolumn{2}{|c|}{ Chemotoxicity } & $\begin{array}{l}\text { Weight Changes } \\
\text { (percentage in } \\
\text { bracket) }\end{array}$ & $\begin{array}{c}\text { Appetite Changes } \\
\text { (percentage in } \\
\text { bracket) }\end{array}$ \\
\hline \multirow{4}{*}{$1^{\text {st }}$ Cycle } & Increased & $12(24 \%)$ & - \\
\hline & Decreased & $38(76 \%)$ & $38(76 \%)$ \\
\hline & No change & - & $12(24 \%)$ \\
\hline & Total & $50(100 \%)$ & $50(100 \%)$ \\
\hline \multirow{5}{*}{$3^{\text {rd }}$ Cycle } & Increased & $12(24 \%)$ & - \\
\hline & Decreased & $38(76 \%)$ & $38(76 \%)$ \\
\hline & No change & - & $12(24 \%)$ \\
\hline & Total & $50(100 \%)$ & $50(100 \%)$ \\
\hline & $P$ value & 0.815 & 0.815 \\
\hline \multirow{5}{*}{$6^{\text {th }}$ Cycle } & Increased & $12(24 \%)$ & - \\
\hline & Decreased & $38(76 \%)$ & $38(76 \%)$ \\
\hline & No change & - & $12(24 \%)$ \\
\hline & Total & $50(100 \%)$ & $50(100 \%)$ \\
\hline & $P$ value & 0.815 & 0.815 \\
\hline \multicolumn{4}{|c|}{ Table 5. Prevalence of Weight \& Appetite Changes } \\
\hline
\end{tabular}

Results of the study are given in Table 2, 3, 4 \& 5. Total of $32 \%$ patients had leucopenia, single or multiple times during chemotherapy. Amongst 16 patients, leucopenia was observed 21 times during chemotherapy with statistically significant trend in increasing severity when compared between $1^{\text {st }} \& 3^{\text {rd }}$ cycle; but the trend of severity was statistically insignificant between $3^{\text {rd }} \& 6^{\text {th }}$ cycle.

Total $30 \%$ patients had thrombocytopenia, single or multiple times during chemotherapy. Amongst 15 patients there was 22 times of occurrences of thrombocytopenia with statistically insignificant trend.

In this study apart from $80 \%$ prevalence of nail changes amongst study population who received cyclophosphamide (AC) with paclitaxel group, no other finding was statistically significant proving one specific regimen superior or inferior to others with respect to chemotoxicity.

In this study there was minimal prevalence of severe grades of chemotoxicity with no life-threatening event.

\section{DISCUSSION}

The treatment modalities for carcinoma breast take heavy toll on the overall health of the patient; physically, socially or mentally. Especially chemotherapy. With all the cytotoxic drugs used, prevalence of side effects of chemotherapy is also significant as is their therapeutic potential.

\section{Nail Changes}

Several of the drugs from class of anthracyclines \& taxanes are known to cause toxic changes in nails namely drug induced nail pigmentation (DHNP) most frequent of them; onycholysis, paronychia, subungual or periungual erythema, etc. (Table 2, 3) In this study patients with AC \& paclitaxel combination had more prevalence ( $80 \%$ ) of nail changes than other regimens, but the regimen was a combination of two different drugs anthracycline $\&$ taxane, both of which are known to cause nail changes \& were used in combination with each other in this regimen. So, exact analysis \& conclusion could not be drawn for sub regimen that was more toxic. Can G et al. 2012,16 in their study had $50.5 \%$ of prevalence with increasing trend in severity which was a consistent finding with this study. While 
in a study Yorulmaz et al. 2016,11 concluded a prevalence of $34.1 \%$ which was an inconsistent finding with this study, but they also concluded that no specific regimen was more toxic in terms of nail changes which was consistent with this study. In this study, along with nail pigmentation, tongue pigmentation was also noted in one patient.

\section{Hair Loss}

Hair loss is a toxicity of chemotherapy drugs that has a high impact on the psychological well-being of the patient. ${ }^{17}$ In this study only one patient from AC regimen did not have hair loss. (Table 2, 3) In their study, Partridge et al. 2001, ${ }^{9}$ found more than $95 \%$ of prevalence of alopecia which was a consistent finding with indexed study.

In another interventional study, Kinoshita et al. 2019,18 compared prevalence of alopecia in patients undertaking chemotherapy using scalp cooling device and in a control group without such device. It had resulted in $100 \%$ prevalence amongst patients in control group which is a consistent finding with this study.

In this study $4 \%$ of patients also reported of having loss of eyelashes (madarosis) which is a known toxicity of chemotherapy. ${ }^{19}$

\section{Nausea}

Out of the $100 \%$, only $6 \%$ of patients experienced grade 3 nausea, those 3 patients hailed from 3 different regimens AC with paclitaxel, AC regimen \& 5-fluorouracil (CAF) regimen each. (Table 2, 4)

There was statistically significant decreasing trend of severity which was consistent with Montemurro et al. 2015,13 but inconsistent with Hayashi et al. 2019,20 \& Buzdar et al. 1999,12 which showed less prevalence of nausea of $46.66 \%$ than indexed study and CAF regimen being more toxic than others respectively as compared to indexed study where no particular regimen was more toxic. Increased prevalence can be attributed to nausea being subjective and psychological feeling of being unwell which may vary in different study population.

\section{Vomiting}

(Table 2, 3) Montemurro et al. 2015,13 showed there was statistically significant decreasing trend of severity which was consistent with this study. While Hayashi et al. 2019,20 \& Buzdar et al. 1999,12 showed less prevalence of just $15 \%$ and CAF regimen being more toxic respectively which were inconsistent findings with this study.

\section{Weight Changes}

The causes of weight gain in a patient of carcinoma breast undergoing chemotherapy are given as fat accumulation \& alteration in the deposition of body fat that results due to hormonal changes as result of amenorrhoea secondary to chemotherapy drugs. ${ }^{21}$ (Table 2,5 )

This study had results of more patients experiencing weight loss than weight gain. Which are inconsistent findings with studies of Lankester et al. 2001,22 \& Demark-Wahnerfried et al. 2001,23 which showed $64 \%$ patients gaining weight compared to $5 \%$ experiencing weight loss and a median weight gain of $2.1 \mathrm{~kg}$ respectively for both studies. This can be attributed to the fact that most of the patients included in our study group belonged to lower economic strata which meant apathy towards general health on patient's part as well as economic, social, psychological problems affecting the diet of the patient.

Demark-Wahnerfried et al. $2001,{ }^{23}$ showed increase in the weight of the study population attributing to sarcopenic obesity which is weight gain in the presence of lean tissue loss or absence of lean tissue gain.

\section{Appetite Changes}

(Table 2, 5) Montemurro et al. 2015,13 in their study showed $54 \%$ subjects experiencing reduced appetite, inconsistent with this study having more prevalence of the same. More prevalence can be resulted because of poor patient tolerance to chemotherapy drugs due to multiple factors like increased nausea, vomiting, reduced mental health status, increased fatigue, anaemia, neutropenia resulting in reduced overall health status of the patient which resulted in reduced appetite of the study population.

\section{Fatigue}

Findings of $100 \%$ prevalence of varying grades with significantly increasing trend of severity of fatigue was consistent with similar results of Broeckel et al. 1998.10 (Table $2,3)$.

\section{Leucopenia}

(Table 2, 4) Findings of this study was inconsistent with studies done by Partridge et al. 2001,9 \& Buzdar et al. 1999,12 with both studies having more prevalence (51 - $95 \%$ \& $42.5 \%$ respectively) as well as Buzdar et al. 1999,12 having more subjects with higher grades of leucopenia with paclitaxel being more toxic than CAF regimen.

\section{Thrombocytopenia}

Amongst $30 \%$ (15 out of 50) patients of this study there was 22 times occurrences of thrombocytopenia with statistically insignificant trend. (Table 2, 4) which was inconsistent with the study of Partridge et al. 2001,9 showing prevalence of 6 $20 \%$ for AC regimen; 21 - $50 \%$ for CAF regimen.

The results of the study were compared with other studies. Partridge et al. 2001, ${ }^{9}$ did a meta-analysis over the prevalence of short term as well as long term chemotoxicities in patients of carcinoma breast who received any form of chemotherapy with different regimens including cyclophosphamide, methotrexate, and 5-fluorouracil (CMF); doxorubicin and cyclophosphamide (AC); cyclophosphamide, doxorubicin, and 5-fluorouracil (CAF); 5-fluorouracil, epirubicin, and cyclophosphamide (FEC); methotrexate and 5-fluorouracil 
(MF) and the results were frequent prevalence (51 - 95 \%) for nausea and neutropenia, common prevalence (21 - $50 \%$ ) for vomiting, uncommon prevalence $(6-20 \%)$ for thrombocytopenia, almost always prevalence (> $95 \%$ ) for alopecia and almost no prevalence $(<1 \%)$ for neuropathy for $\mathrm{AC}$ regimen; whereas always prevalence $(>95 \%)$ for alopecia, frequent prevalence (51 - $95 \%)$ for neutropenia, thrombocytopenia, common prevalence $(21$ - $50 \%)$ for vomiting and nausea, uncommon prevalence (6 - $20 \%$ ) for neuropathy for CAF regimen. Broeckel et al. 1998,10 compared prevalence of fatigue between a group of women who received adjuvant chemotherapy and a control group of healthy women. And the results were average level of fatigue experienced by women previously treated with adjuvant chemotherapy was approximately $50 \%$ greater than that reported by a comparison group of women with no history of cancer. Additional findings suggested that these differences were clinically as well as statistically significant. Yorulmaz et al. 2016,11 studied prevalence of nail changes in patients receiving adriamycin \& paclitaxel. $34.1 \%$ of the patients demonstrated clinical signs of nail pigmentation.

Nail pigmentation was observed in $30.8 \%$ of patients, who had received doxorubicin; in $35.7 \%$ of patients, who had received taxanes (docetaxel and paclitaxel). There was no statistically significant relationship between the nail pigmentation and the type of the chemotherapeutic regimen administered, Buzdar et al. 199912 compared side effects between paclitaxel \& CAF. The observations were $21 \%$ prevalence of grade 3 nausea in CAF with $10 \%$ in paclitaxel group; $7 \%$ grade 3 vomiting in CAF to $2 \%$ in paclitaxel; $16 \%$ grade 3 stomatitis in CAF to $13 \%$ in paclitaxel; $9 \%$ paraesthesia in CAF to $51 \%$ in paclitaxel; $21 \%$ prevalence of neutropenia in CAF to $53 \%$ in paclitaxel.

Montemurro et al. 2015,13 conducted a study in Italy on 604 patients irrespective of the regimen receiving chemotherapy for carcinoma breast in 11 centres. They tabulated the observations for prevalence \& severity of nausea during chemotherapy as per CTCAE grading version 4 . They concluded that there was decreasing trend in prevalence as well as severity of nausea and vomiting in the patients while $54 \%$ prevalence with no trend in either increase or decrease in severity for appetite; there was $77 \%$ of prevalence of fatigue in the study population with no significant increase in severity along the course of chemotherapy. Very few similar studies were conducted in India where patients have different physical, mental, social \& cultural characteristics that affect the response \& outcomes of treatment differently and many patients still end up as defaulters as chemotoxicities affect their quality of life seriously.

\section{CONCLUSIONS}

Different chemotoxicities have different prevalence, peaking at different times during the course of chemotherapy with different trends of severity which will help the medical practitioners and the patients to watch out for the probable causes leading to defaulters at different times during the course and thereby formulating guidelines regarding the prevention of the same.

\section{Limitations}

Long term chemotoxicity parameters could not be observed adequately due to time constraint.

Data sharing statement provided by the authors is available with the full text of this article at jemds.com.

Financial or other competing interests: None.

Disclosure forms provided by the authors are available with the full text of this article at jemds.com.

\section{REFERENCES}

[1] Ferlay J, Soerjomataram I, Dikshit R, et al. Cancer incidence and mortality worldwide: sources, methods and major patterns in GLOBOCAN 2012. Int J Cancer 2015;136(5):E359-86.

[2] Gupta A, Shridhar K, Dhillon PK. A review of breast cancer awareness among women in India: cancer literate or awareness deficit? Eur J Cancer 2015;51(14):2058-66.

[3] Babu GR, Lakshmi SB, Thiyagarajan JA. Epidemiological correlates of breast cancer in South India. Asian Pac J Cancer Prev 2013;14(9):5077-83.

[4] Ali I, Wani WA, Saleem K. Cancer scenario in India with future perspectives. Cancer Ther 2011;8:56-70.

[5] Reddy KS, Shah B, Varghese C, et al. Responding to the threat of chronic diseases in India. Lancet 2005;366(9498):1744-9.

[6] Balasubramaniam SM, Rotti SB, Vivekanandam S. Risk factors of female breast carcinoma: a case control study at Puducherry. Indian J Cancer 2013;50(1):65-70.

[7] Kuraparthy S, Reddy KM, Yadagiri LA, et al. Epidemiology and patterns of care for invasive breast carcinoma at a community hospital in Southern India. World J Surg Oncol 2007;5(1):56.

[8] Kayl AE, Meyers CA. Side-effects of chemotherapy and quality of life in ovarian and breast cancer patients. Curr Opin Obstet Gynecol 2006;18(1):24-8.

[9] Partridge AH, Burstein HJ, Winer EP. Side effects of chemotherapy and combined chemohormonal therapy in women with early-stage breast cancer. J Natl Cancer Inst Monogr 2001;(30):135-42.

[10] Broeckel JA, Jacobsen PB, Horton J, et al. Characteristics and correlates of fatigue after adjuvant chemotherapy for breast cancer. J Clin Oncol 1998;16(5):1689-96.

[11] Yorulmaz A, Dogan M, Artuz F, et al. Comparison of pigmentary side effects of taxanes and anthracyclines: an onychoscopic evaluation. Cutan Ocul Toxicol 2017;36(2):135-9.

[12] Buzdar AU, Singletary SE, Theriault RL, et al. Prospective evaluation of paclitaxel versus combination chemotherapy with fluorouracil, doxorubicin and cyclophosphamide as neoadjuvant therapy in patients with operable breast cancer. J Clin Oncol 1999;17(11):3412-7. 
[13] Montemurro F, Mittica G, Cagnazzo C, et al. Self-evaluation of adjuvant chemotherapy-related adverse effects by patients with breast cancer. JAMA Oncol 2016;2(4):44552.

[14] Prigerson HG, Bao Y, Shah MA, et al. Chemotherapy use, performance status and quality of life at the end of life. JAMA Oncol 2015;1(6):778-84.

[15] Hay JL, Atkinson TM, Reeve BB, et al. Cognitive interviewing of the US National Cancer Institute's patient -reported outcomes version of the common terminology criteria for adverse events (PRO-CTCAE). Quality of Life Research 2014;23(1):257-69.

[16] Can G, Aydiner A, Cavdar I. Taxane-induced nail changes: predictors and efficacy of the use of frozen gloves and socks in the prevention of nail toxicity. Eur J Oncol Nurs 2012;16(3):270-5.

[17] Villasante AC, Herskovitz I, Mauro LM, et al. Chemotherapy- induced alopecia. J Clin Invest Dermatol 2014;2(2):8.

[18] Kinoshita T, Nakayama T, Fukuma E, et al. Efficacy of scalp cooling in preventing and recovering from chemotherapy-induced alopecia in breast cancer patients: the HOPE study. Front Oncol 2019;9:733.
[19] Morris C, Woodward J, Stinnett S. The role of bimatoprost eyelash gel in chemotherapy-induced madarosis: an analysis of efficacy and safety. Int J Trichology 2011;3(2):84-91.

[20] Hayashi M, Nakazawa K, Hasegawa Y, et al. Risk analysis for chemotherapy-induced nausea and vomiting (CINV) in patients receiving FEC100 treatment. Anticancer Res 2019;39(8):4305-14.

[21] Helms RL, O'Hea EL, Corso M. Body image issues in women with breast cancer. Psychol Health Med 2008;13(3):313-25.

[22] Lankester KJ, Phillips JE, Lawton PA. Weight gain during adjuvant and neoadjuvant chemotherapy for breast cancer: an audit of 100 women receiving FEC or CMF chemotherapy. Clin Oncol (R Coll Radiol) 2002;14(1):647.

[23] Demark-Wahnefried W, Peterson BL, Winer EP, et al. Changes in weight, body composition and factors influencing energy balance among premenopausal breast cancer patients receiving adjuvant chemotherapy. J Clin Oncol 2001;19(9):2381-9. 